\title{
Cerebellar projections to the red nucleus and inferior olive originate from separate populations of neurons in the rat: a non-fluorescent double labeling study
}

\author{
T.M. Teune *, J. van der Burg, T.J.H. Ruigrok \\ Department of Anatomy, Erasmus University, PO Box 1738, 3000 DR Rotterdam, The Netherlands
}

Accepted 6 December 1994

\begin{abstract}
In the rat, the extent of collateralization of projections from the cerebellar nuclei to the red nucleus and inferior olive was investigated using a retrograde double labeling technique. The combination of tracers selected, cholera toxin- $\beta$-subunit and WGA-BSA-gold, not only enabled the use of small injection sites but also resulted in clearly distinguishable and permanently stained neurons that could be analyzed in counterstained sections.
\end{abstract}

Keywords: Cerebellar nucleus; Inferior olive; Red nucleus; Cholera toxin $\beta$-subunit; Gold-lectin tracer; Axon collateral

Light microscopic analysis of the contralateral cerebellar nuclei confirmed the generally held belief that neurons projecting to the magnocellular part of the red nucleus are mainly found in the interposed nuclei whereas those projecting to its parvicellular part are predominantly located in the lateral cerebellar nucleus. Small neurons, retrogradely labeled from the inferior olive, are scattered throughout all divisions of the cerebellar nuclei. In all cases, less than $0.5 \%$ of all labeled neurons contained both labels indicating that these cells may project to the red nucleus as well as to the inferior olive.

These findings support and strengthen the concept that the projection from the cerebellar nuclei to the red nucleus and inferior olive originates from different sets of neurons which, consequently, may transmit different information.

The cerebellar nuclei, together with the vestibular nuclei, are the targets of the Purkinje cells of the cerebellar cortex. The output of the cerebellar nuclei $(\mathrm{CN})$ is directed, predominantly via the superior cerebellar peduncle, to a variety of brain stem structures in thalamus, mesodiencephalon and medulla $[13,17,18]$. Detailed projections have been described to the red nucleus [3,14] and the inferior olive [30]. It has been

\footnotetext{
${ }^{*}$ Corresponding author. Fax: (31) (10) 4365780.
}

shown in the rat $[4,19,25]$ and the cat [15] that the nucleo-olivary projection is likely to be completely derived from GABAergic neurons. The projertions to the red nucleus appear to be excitatory as demonstrated with electrophysiological [33] and immunohistochemical $[9,23]$ techniques. GABA has been identified as a neurotransmitter in the red nucleus [2,35]. It has been attributed to interneurons [20,24], but a contribution of ascending collaterals of GABAergic nucleo-olivary fibers has not been excluded.

The cells of origin of the nucleo-olivary projections are small (see [21] for references). Neurons projecting to the red nucleus have not been measured, but those projecting to the thalamus are estimated to be generally larger (cat: [21,32]). Populations of small GABAimmunoreactive neurons (mean diameter 10-22.5 $\mu \mathrm{m}$, peak near $10 \mu \mathrm{m}$ ) and larger glutamate-immunoreactive neurons (mean diameter $10-35 \mu \mathrm{m}$, peak at about $20 \mu \mathrm{m}$ ) were distinguished by Batini et al. [6] in the cerebellar nuclei of the rat.

However, several electrophysiological studies in the cat $[1,5,22,32]$ indicate that a substantial contingent of nucleo-olivary projections may have ascending collaterals. Fluorescent double retrograde tracing studies by Bentivoglio and colleagues in the rat $[7,8]$ and by Bharos et al. [11] in the cat with tracer combinations injected in thalamus and caudal medulla resulted in many single labeled small-sized nucleo-olivary neurons 

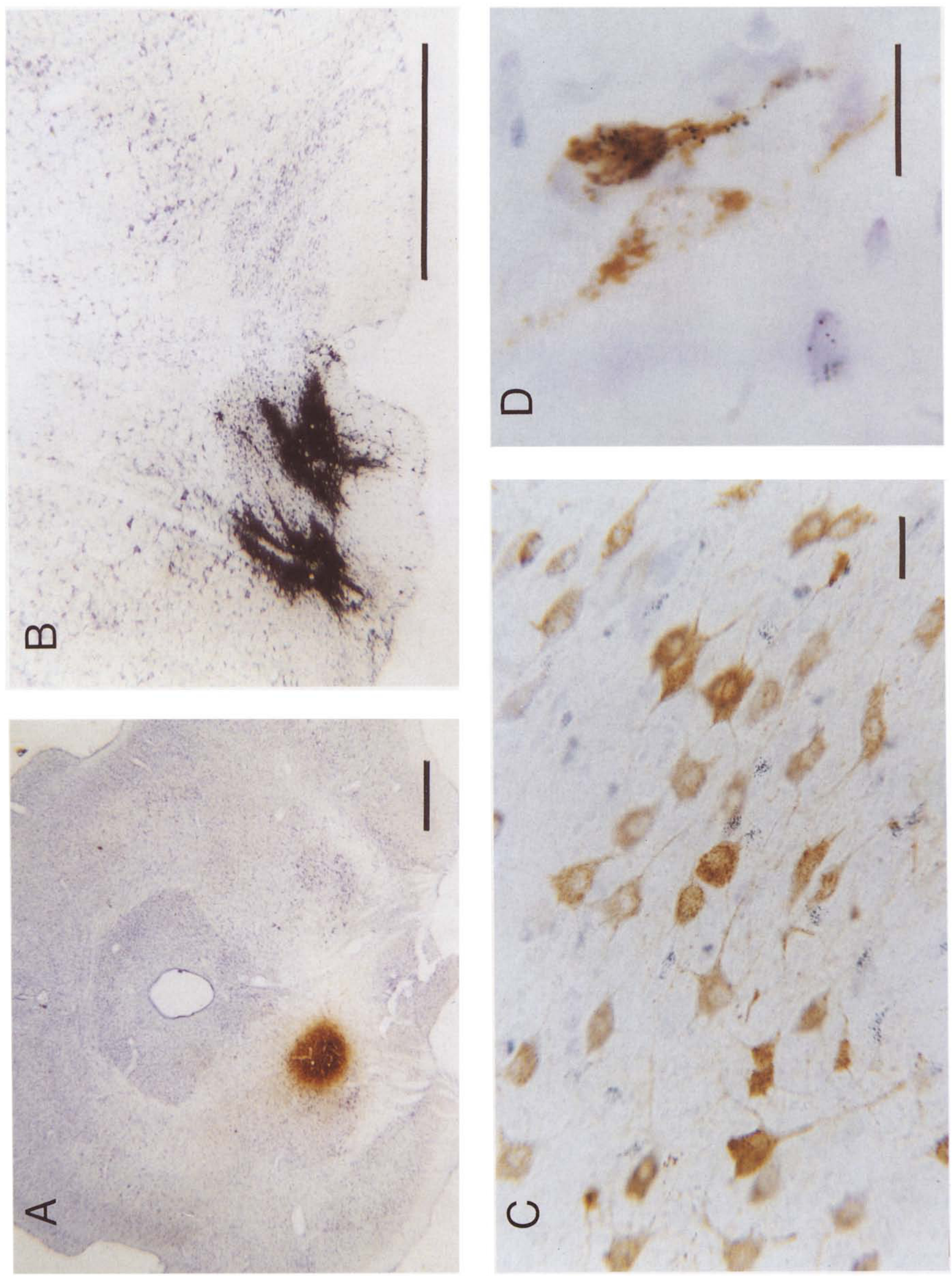

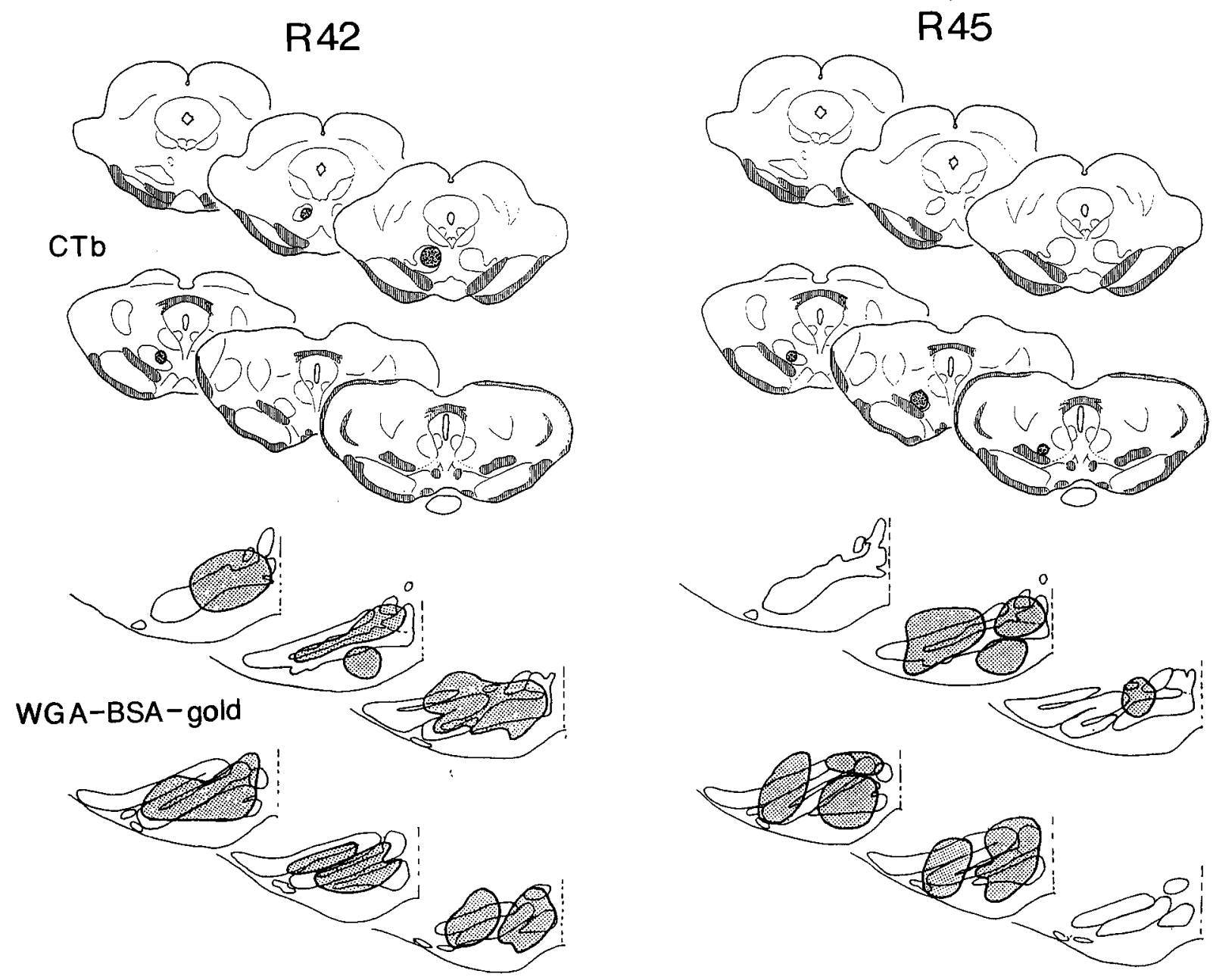

Fig. 2. Diagrammatic representations of the injection sites in the RN and IO of cases R42 and R45.

but also in a contingent of double labeled larger neurons located in specific subdivisions of the cerebellar nuclei. No double labeled cells were observed by Legendre and Courville [21] in their experiments with injections of fluorescent tracers in the inferior olive and the thalamus of the cat. We decided to reinvestigate the collateralization of nucleo-olivary fibers to the red nucleus of the rat, because no experiments with double labeling from injections delivered to the red nucleus and the inferior olive have been reported. A non-fluorescent double retrograde tracing technique [29], making use of cholera toxin $\beta$-subunit (CTb) and a gold-lectin conjugate, was used in this study. This combination ensures small injection sites, permanently and easily discriminated retrograde labeling of neurons, and the possibility to examine the resultant labeling in counterstained sections with the light microscope. Since the red nucleus (RN) is classically divided into a caudally positioned magnocellular part (RNm) and a parvicellular rostral pole ( $\mathrm{RNp}$ ) [27], injections were centered on either of these different parts in order to study potential differences in collateralization to these two areas and to the inferior olive (IO).

Male Wistar rats $(n=12)$, weighing $200-250 \mathrm{~g}$, were anesthetized with sodium-pentobarbital $(120 \mathrm{mg} / \mathrm{kg}$, i.p.) and mounted in a stereotactic frame. Glass micropipettes (tip diam. 10-15 $\mu \mathrm{m}$ ) were initially placed based on coordinates from the atlas by Paxinos and Watson [26], and prior to injection the final site was verified by recording the characteristic firing of either rubral or olivary cells. CTb (low salt: List Biol. Lab., Campbell, CA) was applied iontophoretically to the red nucleus ( $4 \mu \mathrm{A}$ positive current, for $30 \mathrm{~min}$ with a 7 $\mathrm{s}$ on, $7 \mathrm{~s}$ off cycle: Fig. 1A). The gold-lectin conjugate consisted of $10 \mathrm{~nm}$ gold sol (Aurion, Wageningen, the Netherlands) conjugated to wheatgerm agglutinin and

Fig. 1. Color microphotographs showing retrograde double labeling experiments with $\mathrm{CTb}$ and WGA-BSA-gold. A: CTb injection site centered on RNm in case R42. B: WGA-BSA-gold injection site in the inferior olive (case R42). C: retrogradely labeled cells in the LCN of case R45. Medium and large-sized neurons projecting to the $\mathrm{RNp}$ are labeled with brown DAB reaction product and are intermingled with small neurons containing black gold-silver particles, indicating their termination in the IO. D: retrogradely labeled neurons in the interposed nucleus. Note that one neuron contains both labels. Bar represents $1 \mathrm{~mm}$ in $\mathrm{A}$ and $\mathrm{B}$, and $25 \mu \mathrm{m}$ in $\mathrm{C}$ and $\mathrm{D}$. 
bovine serum albumin (WGA-BSA), prepared according to Roth [28], and was pressure injected through a glass micropipette (tip diameter 12-16 $\mu \mathrm{m}$ ) into the inferior olivary complex, ipsilateral to the $\mathrm{CTb}$ injection. A total of 200-300 nl WGA-BSA-gold was injected using multiple injection tracks in order to obtain

\section{$\mathrm{R} 42$}
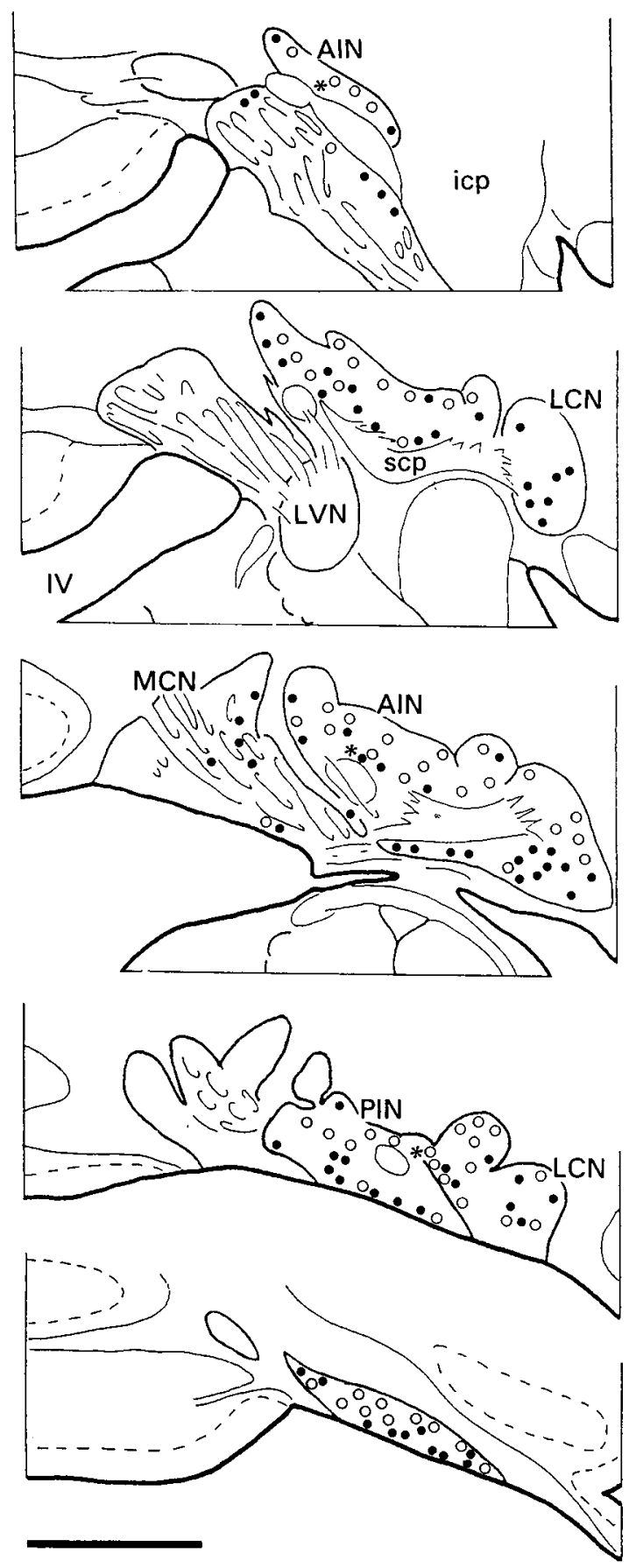

a large injection site but to spare the reticular formation overlying the olive (Fig. 1B). After a survival time of 7-10 days, the animals were perfused with $300 \mathrm{ml}$ of a $0.8 \% \mathrm{NaCl}, 0.8 \%$ sucrose, $0.4 \%$ d-glucose solution in $0.05 \mathrm{M}$ phosphate buffer (PB, pH 7.3), which was followed by $4 \%$ paraformaldehyde, $0.1 \%$ glutaralde-

R45
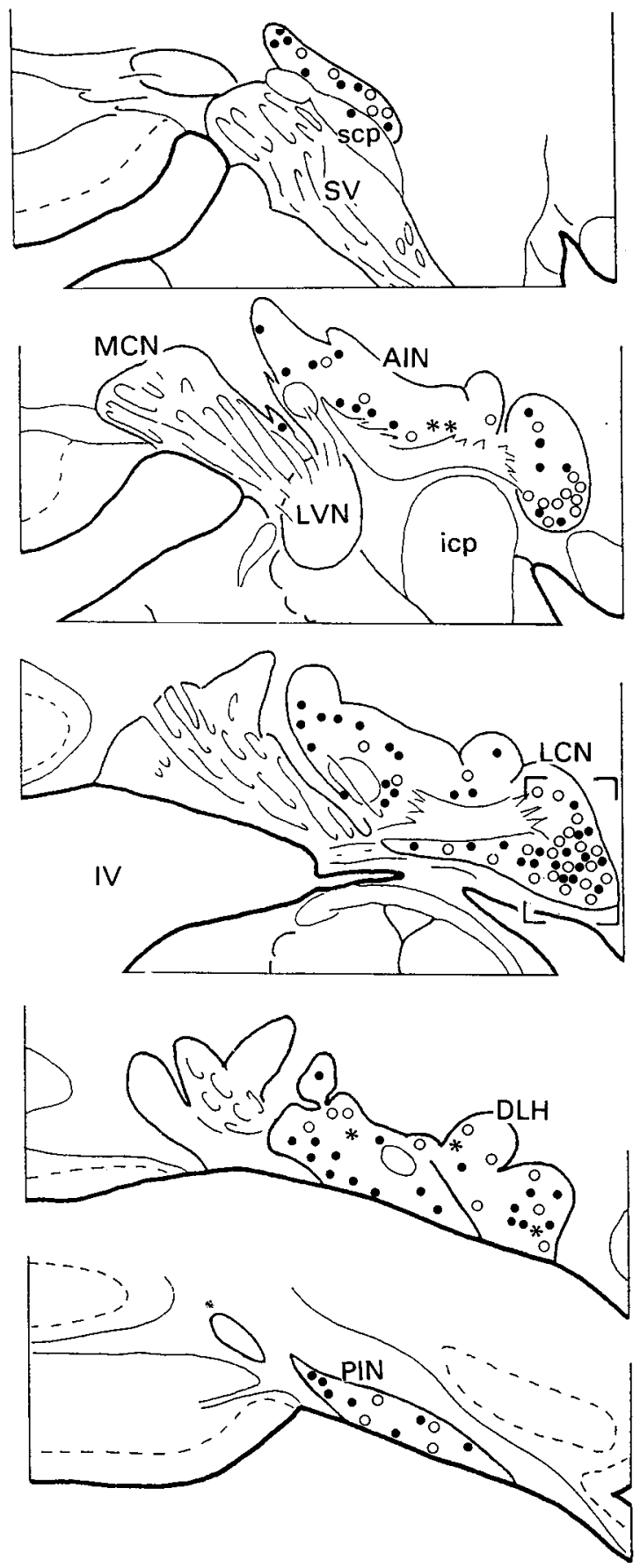

Fig. 3. Diagrammatic representation of the retrograde labeling in the contralateral $\mathrm{CN}$ of cases R42 and R45. CTb labeled neurons are indicated by open circles (approximately one circle for every five labeled cells), gold-silver labeled neurons are indicated by dots (approximately one dot for every five labeled cells). All double labeled neurons are indicated by an asterisk. 
hyde and $4 \%$ sucrose in PB. The brains were removed, blocked, embedded in gelatin and cryoprotected in $30 \%$ sucrose in $0.05 \mathrm{M}$ PB. Transverse sections (40 $\mu \mathrm{m}$ ) were cut on a freezing microtome and collected in $0.1 \mathrm{M} \mathrm{PB}$. Free floating sections were incubated at $4^{\circ} \mathrm{C}$ in the dark with constant agitation in anti-CTb (List Biol. Lab.), dilution 1:15,000 in Tris buffer containing $0.5 \mathrm{M} \mathrm{NaCl}$ and $0.5 \%$ Triton X-100 (TBS +, $\mathrm{pH}$ 8.6) for 72 hours. After rinsing, the sections were subsequently incubated at room temperature in biotinylated donkey anti-goat (List Biol. Lab., dilution 1: 2000 in TBS +) for $2 \mathrm{~h}$, rinsed and reacted with the avidinebiotine-complex (ABC Elite kit, Vector, Burlingame $\mathrm{CA}$ ) for $2 \mathrm{~h}$ and, finally, reacted with diaminobenzidine (DAB: $37,5 \mathrm{mg}$ in $150 \mathrm{ml}$ Tris- $\mathrm{HCl}$, pH 7.6 with $25 \mu \mathrm{l}$ $30 \% \mathrm{H}_{2} \mathrm{O}_{2}$ ) for $30 \mathrm{~min}$. Next, sections were silver intensified (Aurion), mounted, counterstained and coverslipped with Permount.

Light microscopic examination showed numerous labeled neurons within the $\mathrm{CN}$ contralateral to the injection sites (Fig. 1C,D). Double labeled cells could be easily distinguished from unlabeled or single labeled cells since the characteristic small, black, gold-silver particles can be clearly distinguished from the brown $\mathrm{DAB}$ reaction product indicating $\mathrm{CTb}$ labeling.
Two representative experiments (R42 and R45) will be described. In R42, as shown in Fig. 2, the CTb injection was centered on the RNm (see also Fig. 1A), whereas the RNp was injected in case R45. In both animals, the WGA-BSA-gold injection covered approximately $80 \%$ of the ipsilateral IO (Fig. 1A, Fig. 2). For both cases, the resulting retrograde labeling in the contralateral $\mathrm{CN}$ is shown in Fig. 3. The location of $\mathrm{CTb}$ positive cells and gold-silver labeled cells are represented as one dot per 5 labeled cells. Each double labeled cell is indicated individually. The injection located in the RNm (R42) resulted in labeling of medium to large neurons which were mainly found within the interposed nuclei and, occasionally, within the lateral cerebellar nucleus (LCN). Case R45 resulted in labeling of neurons predominantly located in the LCN. Labeling originating from the IO injection was observed in small cells throughout the CN. Double labeled cells (less than $0.5 \%$ of all labeled cells) were found only rarely in the interposed nuclei (R42) or in the LCN (R45) and are medium- to large-sized (Fig. 4). Fig. 5 shows a camera lucida drawing from part of the LCN of case R45 to give an impression of the distribution of the labeled neurons. In this particular area of the chosen section, both gold-silver labeled and $\mathrm{CTb}$

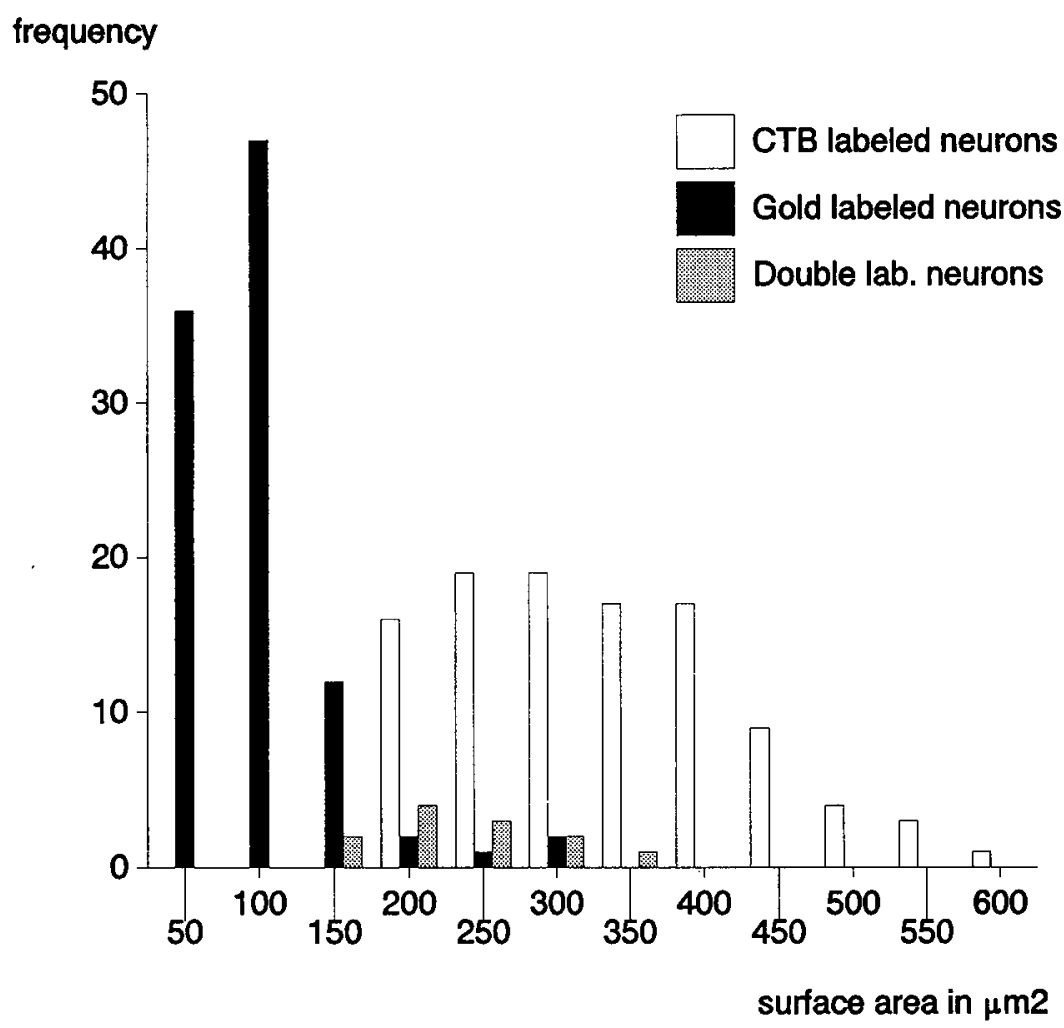

Fig. 4. Size distribution of single and double labeled neurons. One hundred CTb and one hundred gold labeled neurons were chosen and measured randomly and were supplemented with 12 double labeled neurons. Surface area was estimated by the formula $1 / 4 \pi \mathrm{lw}$, where 1 equals the length and $w$ the width of the neuron. Note that the size distributions of the single, gold or CTb, labeled neurons are almost completely separated and that the double labeled neurons fall within the size distribution of the CTb neurons. The overal size distribution is quite similar to data reported by Chan-Palay [13]. 


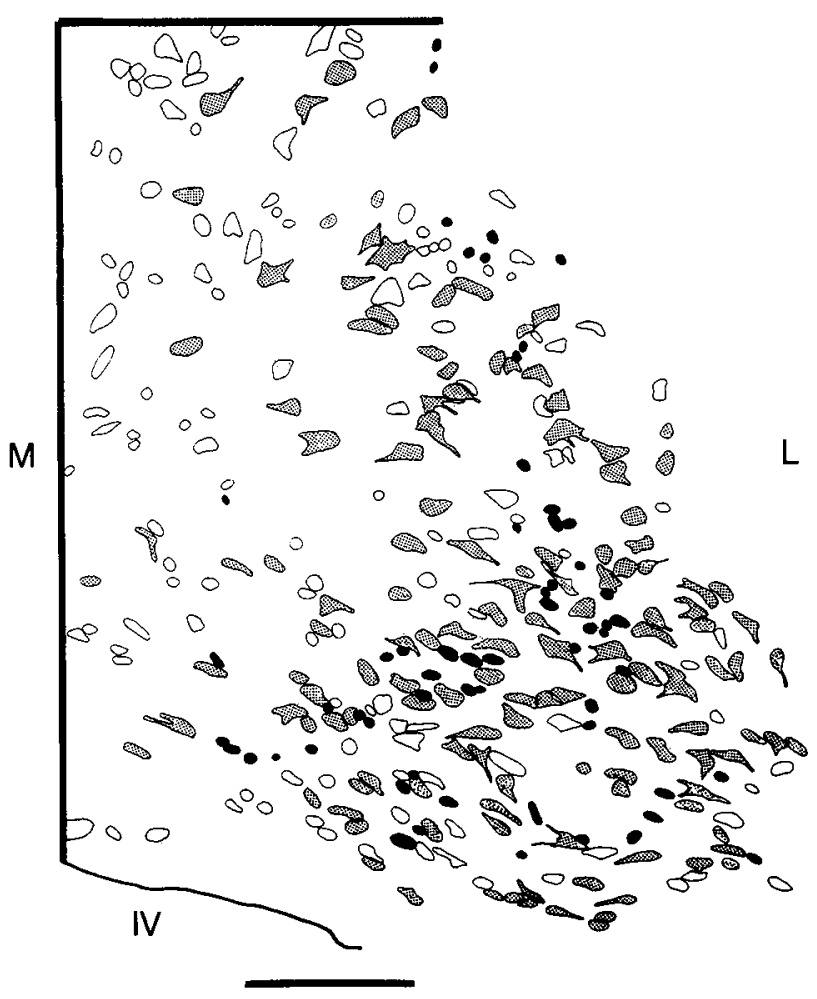

Fig. 5. Camera lucida drawing of part of the LCN in case R45. Non-labeled cells are indicated by open contours, shaded contours denote CTb labeled neurons, black contours indicate gold-silver labeled neurons. No double labeled cells were encountered. Bar equals $100 \mu \mathrm{m}$.

labeled neurons were abundantly present, leaving only a relatively small amount of non-labeled neurons. However, here, not a single double labeled cell was observed (see also Fig. 1C). Note that all gold-labeled neurons fall within the small-sized category.

Results from our experiments indicate that only a very small number of $\mathrm{CN}$ neurons may collateralize to the RN and IO, since less than $0.5 \%$ of all labeled cells were double labeled through the application of tracers in the RN and IO. This number is clearly less than may be concluded from the experiments of Bentivoglio [7] with large injections of fluorescent tracers in the caudal medulla and the thalamus [7]. However, as indicated by these authors, definite conclusions on the collateralization of nucleo-thalamic and nucleo-olivary projections could not be drawn from this study, because the $\mathrm{CN}$ also project to extra-olivary areas in the caudal medulla and to the spinal cord $[12,13,18]$. Although the injection sites in the present study were much smaller, inadvertent labeling of passing fibers destined for the spinal cord or extra-olivary medullary regions may be responsible for double labeling a few neurons with projections to the red nucleus in our experiments. Especially, since the diameters of these double labeled neurons exceed the diameters of single labeled nucleo-olivary neurons but fit into the size distribution of single labeled nucleo-rubral neurons (Fig. 4). Consequently, we conclude that in the rat, most, if not all, nucleo-olivary neurons do not posses ascending collaterals that terminate within the RN. This conclusion is identical to the conclusions of Legendre and Courville [21] from their fluorescent double labeling study in the cat with injections of the inferior olive and the thalamus.

Nevertheless, electrophysiological observations in the cat, of collisions of antidromically evoked action potentials of individual neurons in the cerebellar nuclei after stimulation of the RN and IO [1,5,11,22,32], suggest that such collateralization indeed may occur. However, these data must be interpreted with caution. Especially for projections from the lateral and anterior interposed nuclei, it is very difficult to follow the course of the nucleo-olivary fibers directly after the decussation [21] and it cannot be ruled out that some fibers may ascend to the level of the RN before descending to the IO and therefore may be stimulated by an electrode placed near the RN. Also, as mentioned above, collaterals of nucleo-rubral fibers may terminate in the vicinity of the $\mathrm{IO}$, e.g. within the ventromedial reticular formation or may descend along the IO to the spinal cord [12] and may be inadvertantly activated by the IO stimulation electrode.

Our data are in accordance with the evidence that the nucleo-olivary projection takes its origin from a population of small GABAergic neurons located in the cerebellar nuclei $[4,15,19]$ whereas the projection to the RN $[9,31,33]$ as well as to the adjacent prerubral area and medial nuclei at the mesodiencephalic junction arises from a population of non-GABAergic and excitatory neurons $[6,10,16]$. Hence, cerebellar projections to the RN and IO evidently originate from completely separate populations. Therefore, although both types of projection neurons are largely intermingled (Fig. 1C, Fig. 5) and, thus, in theory, may be influenced by efferents from a single Purkinje cell zone, elements of both groups are not necessarily activated in the same way. E.g recent evidence suggests that climbing fiber collaterals do not appear to innervate the GABAergic nucleo-olivary neurons [34], indicating that olivary activity may have different monosynaptic effects on nucleo-olivary and nucleo-rubral neurons.

The technical expertise of Mrs. H. Sabel-Goedknegt is gratefully acknowledged. T.M.T. is supported by NWO Grant 900-550-107.

[1] Andersson, G. and Hesslow, G., Activity of Purkinje cells and interpositus neurones during and after periods of high frequence climbing fibre activation in the cat, Exp. Brain Res., 67 (1987) 533-542.

[2] Andre, D., Vuillon-Cacciuttolo, G. and Bosler, O., GABA nerve endings in the rat red nucleus combined detection with serotonin terminals using dual immunocytochemistry, Neurosci., 23 (1987) 1095-1102. 
[3] Angaut, P. and Cicirata, F., The dentatorubral projection in the rat: an autoradiographic study, Behav. Brain Res., 28 (1988) 71-73.

[4] Angaut, P. and Sotelo, C., The dentato-olivary projection in the rat as a presumptive GABAergic link in the olivo-cerebelloolivary loop. An ultrastructural study, Neurosci. Lett., 83 (1987) 227-231.

[5] Ban, M. and Ohno, T., Projection of cerebellar nuclear neurones to the inferior olive by descending collaterals of ascending fibers, Brain Res., 133 (1977) 156-161.

[6] Batini, C., Compoint, C., Buisseret-Delmas, C., Daniel, H. and Guegan, M., Cerebellar nuclei and the nucleocortical projections in the rat: retrograde tracing coupled to GABA and glutamate immunohistochemistry, J. Comp. Neurol., 315 (1992) 74-84.

[7] Bentivoglio, M. and Kuypers, H.G.J.M., Divergent axon colaterals from rat cerebellar nuclei to diencephalon, mesencephalon, medulla oblongata and cervical cord, Exp. Brain Res., 46 (1982) 339-356.

[8] Bentivoglio, M. and Molinari, M., Crossed divergent axon collaterals from cerebellar nuclei to thalamus and lateral medulla oblongata in the rat, Brain Res., 362 (1986) 180-184.

[9] Bernays, R.L., Heeb, L., Cuenod, M. and Streit, P., Afferents to the rat red nucleus studied by means of $\mathrm{D}-\left[{ }^{3} \mathrm{H}\right]$ choline and non-selective tracers, Neuroscience, 26 (1988) 601-619.

[10] Berretta, S., Bosco, G., Giaquinta, G., Smecca, G. and Perciavalle, V., Cerebellar influences on accessory oculomotor nuclei of the rat: a neuroanatomical, immunohistochemical, and electrophysiological study, J. Comp. Neurol., 338 (1993) 50-66.

[11] Bharos, T.B., Kuypers, H.G.J.M., Lemon, R.N. and Muir, R.B., Divergent collaterals from deep cerebellar neurons to thalamus and tectum, and to the medulla oblongata and spinal cord: retrograde fluorescent and electrophysiological studies, Exp. Brain Res., 42 (1981) 399-410.

[12] Buisseret-Delmas, C., Yatim, N., Buisseret, P. and Angaut, P., The $\mathrm{X}$ zone and $\mathrm{CX}$ subzone of the cerebellum in the rat, Neurosci. Res., 16 (1993) 195-207.

[13] Chan-Palay, V., Cerebellar Dentate Nucleus: Organization, Cytology and Transmitters, 1977, Springer-Verlag, Berlin, pp. 548.

[14] Daniel, H., Angaut, P., Batini, C. and Billard, J.M., Topographic organization of the interpositorubral connections in the rat. A WGA-HRP study, Behav. Brain Res., 28 (1988) 69-70.

[15] De Zeeuw, C.I., Holstege, J.C., Ruigrok, T.J.H. and Voogd, J., Ultrastructural study of the GABAergic, cerebellar and mesodiencephalic innervation of the cat medial accessory olive: anterograde tracing combined with immunocytochemistry, J. Comp. Neurol., 284 (1989) 12-35.

[16] De Zeeuw, C.I. and Ruigrok, T.J.H., Olivary projecting neurons in the nucleus of Darkschewitsch in the cat receive excitatory monosynaptic input from the cerebellar nuclei, Brain Res., 653 (1994) 345-350.

[17] Faull, R.L.M., The cerebellofugal projections in the brachium conjunctivum of the rat. II. The ipsilateral and contralateral descending pathways, J. Comp. Neurol., 178 (1978) 519-536.

[18] Faull, R.L.M. and Carman, J.B., The cerebellofugal projections in the brachium conjunctivum of the rat. I. The contralateral ascending pathway, J. Comp. Neurol., 178 (1978) 495-518.

[19] Fredette, B.J. and Mugnaini, E., The GABAergic cerebelloolivary projection in the rat, Anat. Embryol., 184 (1991) 225-243.
[20] Katsumaru, H.F., Murakami, F., Wu, J.Y. and Tsukahara, N., GABAergic intrinsic interneurons in the red nucleus of the cat demonstrated with combined immunocytochemistry and anterograde degeneration methods, Neurosci. Res., 1 (1984) 35-44.

[21] Legendre, A. and Courville, J., Origin and trajectory of the cerebello-olivary projection: an experimental study with radioactive and fluorescent tracers in the cat, Neuroscience, 21 (1987) 877-891.

[22] McCrea, R.A., Bishop, G.A. and Kitai, S.T., Morphological and electrophysiological characteristics of projection neurons in the nucleus interpositus of the cat cerebellum, J. Comp. Neurol., 181 (1978) 397-420.

[23] Monaghan, P.L., Beitz, A.J., Larson, A.A., Altschuler, R.A., Madl, J.E. and Mullet, M.A., Immunocytochemical localization of glutamate-, glutaminase- and aspartate aminotransferase-like immunoreactivity in the rat deep cerebellar nuclei, Brain Res., 363 (1986) 364-370.

[24] Murakami, F., Katsumaru, H., Wu, J.Y., Matsuda, T. and Tsukahara, N., Immunocytochemical demonstration of GABAergic synapses on identified rubrospinal neurons, Brain Res., 267 (1983) 357-360.

[25] Nelson, B.J. and Mugnaini, E., Origins of GABAergic inputs to the inferior olive. In P. Strata (Ed.), Origins of GABAergic Inputs to the Inferior Olive, Springer-Verlag, Berlin, 1989, pp. 86-107.

[26] Paxinos, G. and Watson, C., The Rat Brain in Stereotaxic Coordinates, Academic Press, Sidney, 1986.

[27] Reid, J.M., Gwyn, D.G. and Flumerfelt, B.A., A cytoarchitectonic and Golgi study of the red nucleus in the rat, J. Comp. Neurol., 162 (1975) 337-362.

[28] Roth, J., The colloidal gold marker system for light and electron microscopic cytochemistry. In G.R. Bullock and P. Petrusz (Eds.), The Colloidal Gold Marker System for Light and Electron Microscopic Cytochemistry, Academic Press, London, 1983, pp. 217-284.

[29] Ruigrok, T.J.H., Teune, T.M., van der Burg, J. and Sabel, H., A retrograde double labeling technique for light microscopy. A combination of axonal transport of cholera toxin $\beta$-subunit and a gold-lectin conjugate, J. Neurosci. Meth., submitted (1995).

[30] Ruigrok, T.J.H. and Voogd, J., Cerebellar nucleo-olivary projections in rat. An anterograde tracing study with Phaseolus vulgaris-leucoagglutinin (PHA-L), J. Comp. Neurol., 298 (1990) 315-333.

[31] Tarnecki, R., Functional connections between neurons of interpositus nucleus of the cerebellum and the red nucleus, Behav. Brain Res., 28 (1988) 117-125.

[32] Tolbert, D.L., Bantli, H. and Bloedel, J.R., Multiple branching of cerebellar efferent projections in cats, Exp.Brain Res., 31 (1978) 305-316

[33] Toyama, K., Tsukahara, N. and Udo, M., Nature of cerebellar influences upon the red nucleus neurones, Exp. Brain Res., 4 (1968) 292-309.

[34] Van der Want, J., Borsello, T., Rossi, F. and Strata, P., Climbing fibre collateral innervation of the deep cerebellar nuclei in the rat. A combined anterograde tracing and GABA immunoelectronmicroscopic study, Eur. J. Neurosci., Suppl. 7 (1994) 12.

[35] Vuillon-Cacciuttolo, G., Bosler, O. and Nieollon, A., GABA neurons in the cat red nucleus: a biochemical and immunohistochemical demonstration, Neurosci. Lett., 52 (1984) 129-134. 